\title{
Slobodian, Q. (2018). Globalists: The end of empire and the birth of neoliberalism. Cambridge, Massachusetts: Harvard University Press
}

\author{
Alvaro Zapata Rojas \\ Estudiante de Economía en la Pontificia Universidad Católica del Perú (PUCP). \\ e-mail: a20173414@pucp.edu.pe
}

Economics student at the Pontifical Catholic University of Peru (PUCP). e-mail: a20173414@pucp.edu.pe

El término neoliberalismo es polémico e, inclusive, algunos lo consideran como polisémico, en las discusiones académicas y mediáticas actuales; por ello, se pueden encontrar contenidos diversos y hasta contradictorios. El libro de Quinn Slobodian nos ofrece una mirada histórica de la evolución del pensamiento del neoliberalismo desde el siglo XX que permite acercarnos a una forma más completa sobre lo que este fenómeno significa. Su argumento principal, para darle este enfoque diacrónico, parte de ofrecer un recuento de la historia intelectual, el cual pretende complementar aportes académicos de las varias disciplinas de Ciencias Sociales. La propuesta central del autor es entender este fenómeno desde la historia; dando, así, énfasis en sus principales actores, ideas, redes, instituciones y, finalmente, repercusiones en la esfera global. Desde esta narrativa, el autor busca revelar que existen desacertadas y contradictorias preconcepciones sobre el neoliberalismo.

Pues bien, este pensamiento se originó en un grupo de intelectuales y burócratas austriacos, que abogaba por y defendía, desde sus inicios, la existencia de un mercado autorregulado como una entidad autónoma. No obstante, Slobodian nos narra que estos fundadores sabían, contrariamente a este principio, que el mercado no se regulaba de forma autónoma y admitían, más bien, que era algo imposible de lograr -lo que evidencia una carga ideológica contradictoria recurrente que contrastaba con sus discursos. La historia de los principales precursores, Friedrich Hayek y Ludwig von Mises, empieza con el final de la Primera Guerra Mundial, la cual desencadenó una tendencia: la desaparición de los imperios monárquicos (con algunas excepciones) en todo el mundo -como, por ejemplo, la disolución del imperio astro-húngaro. Al mostrar citas de los principales ideólogos, como von Mises, Slobodian pone de manifiesto que existe un anhelo de estos pensadores hacia

Nota editorial: la presente reseña fue recibida el 20/11/19 y aprobada el 21/01/20. 
la figura de los imperios, debido a la poca facultad democrática que tenían estos para intervenir en la economía. Esto se debe a que parte del discurso ideológico de aquellos se fundamentaba en la separación de lo económico y político. Asimismo, esta división sería el principal argumento utilizado por los ideólogos austriacos; pero, al mismo tiempo, expone su preocupación, desde el contexto de la caída del imperio austrohúngaro, por reproducir un orden social que resguarde el mercado, en lugar de creer que esto sucede por sí solo.

Así, los neoliberales de la época no se oponían a la existencia de un Estado, necesariamente; sino, más bien, estaban en contra del modelo de gobierno que se interponía en su proyecto económico. Von Mises, por su parte, estipulaba que el Estado era meramente un "productor de seguridad", el cual poseía el rol en el mantenimiento de la paz y en garantizar los derechos de propiedad. Asimismo, y curiosamente, el economista también estaba a favor de aplicar impuestos, con el fin de cumplir con intereses empresariales. Su preocupación central, de hecho, era el intervencionismo de un gobierno en materia económica y que recurriese a su población para confirmar su legitimidad como un ente regulador. Así, su prioridad era tener un Estado que garantice el orden y la subordinación social, tal como lo hicieron los imperios previamente ${ }^{1}$.

La época posterior a la Primera Guerra Mundial y la Gran Depresión estuvo marcada por la ampliación del derecho al voto popular. Slobodian argumenta que el neoliberalismo surgió como una respuesta ante ello; una respuesta al crecimiento y consolidación de esta naciente democracia. Por ende, cabe decir que esta tendencia era una amenaza para el proyecto neoliberal, ya que interfería, potencialmente, con el mercado. Sin embargo, los austriacos no anhelaban la disolución de los Estados en un mercado global; sino una solución estructurada y regulada entre lo que llamaban imperium y dominium. El autor explica:

There was not one world but two. One was the world partitioned into bounded, territorial states where governments ruled over human beings. This he called the world of imperium [...]. The other was the world of property, where people owned things money, and land scattered across the earth. This was the world of dominium. $[\ldots]$ neoliberals felt he had offered the best description of the world they wanted to conserve. (Slobodian 2018, p.10)

La herramienta principal para lograr dicha estructura fue el derecho. Hayek demostró su escepticismo con respecto a los modelos macroeconómicos de la época. Esto era atribuido a que los neoliberales aceptaban el hecho de que era imposible que los actores puedan entender el mercado en su totalidad. Entonces, los esfuerzos no se enfocaban en modelos matemáticos, sino en modelos de gobernanza con escalas

\footnotetext{
1 Después de la Primera Guerra Mundial, los estados europeos asumieron el rol de ente controlador de capital y propiedad con el fin de reorganizar el desastre de la guerra. Los liberales vieron esto como una restricción al libre mercado y al derecho de propiedad privada. El anhelo a los imperios se debe a la idea de un territorio en que, sin importar diferencias étnicas o políticas, existía un consenso sobre la soberanía económica y al poder autoritario de mantener el orden social.
} 
que articularan lo local a lo global; que encapsularan y protegieran el espacio de la economía mundial. El ámbito legal, por tanto, sería la esfera a la que se trasladarían los precursores para estructurar y materializar su idea de libre mercado. Esto lo lograron mediante la eventual creación de instituciones que brindaban garantías necesarias para consolidar un mercado -aparentemente-despolitizado y en favor de los intereses de los empresarios. Los precursores austriacos describieron esto como una campaña contra el "intervencionismo", pero era intervencionismo por cuenta propia².

De forma cronológica, podemos ver, en el libro, cómo los neoliberales van entrando en constante conflicto con las instituciones internacionales, tales como la Organización de las Naciones Unidas (ONU) o la Organización Internacional del Trabajo (OIT). Los debates se debían a las diferentes propuestas de instituciones globales en el contexto del final de la Segunda Guerra Mundial. Las ideas para articular la globalización variaban entre instituciones de carácter sindicalista y regulador o uno de libre mercado. Un claro ejemplo fue la contundente oposición al $\mathrm{NOEI}^{3}$. Esta organización representaba todo lo que el neoliberalismo rechazaba: sindicatos internacionales, igualitarismo global y una amenaza a la institución de propiedad privada (Slobodian 2018, p 259). $\mathrm{Su}$ principal argumento en contra era que estas nuevas instituciones utilizaban su carácter democrático en la toma de decisiones para frustrar los planes de derecho de propiedad privada en el periodo de descolonización y de industrialización del Sur Global. Lo que nos cuenta Slobodian es que, para los neoliberales, era importante construir un marco legal que garantice las diferencias entre el modo de gobernanza de un territorio y el derecho de propiedad. Al librarse de esas ataduras legales, se podría lograr un mercado más eficiente y "desarrollado". El autor logra hacer un recuento del desarrollo del proyecto neoliberal, el cual abogaba por forjar ligas de naciones, luego en proponer ideas federalistas similares a una unión europea, y finalmente en crear la actual Organización Mundial de Comercio (OMC).

En el proyecto y sus actores persistían ideologías negativas (esencialismos raciales, por parte de Wilhelm Röpke ${ }^{4}$, analogías persuasivas ${ }^{5}$ o argumentos que solo existían por ser contestatarios a políticas que intervenían con sus ideales. Luego, el concepto de que el proyecto neoliberal sí reflejaba la realidad de economía es totalmente erróneo e, inclusive, Hayek llegó a admitir que un mercado perfecto no podía existir debido a la imposibilidad de obtener información completa entre los participantes económicos. El neoliberalismo, luego, dejó de ser un pensamiento que promovía

\footnotetext{
2 Su propuesta era la creación de federaciones de naciones, pues vieron que era imposible eliminar las fronteras políticas. En 1939 Hayek propone la creación de un órgano global (una federación de naciones) necesario para garantizar un "control". Su objetivo era evitar que las naciones individuales crezcan de tal manera que imponga su soberanía sobre las demás y que alteren el mercado mundial. En esa línea, era necesaria y «natural $\gg$ la consolidación de un orden institucional que garantice el funcionamiento del libre mercado.

3 Nuevo Orden Económico Internacional.

4 Fue miembro polémico de la Sociedad de Mont Pelerin. Criticaba ácidamente las políticas de J.F. Kennedy y además compartía abiertamente ideas de esencialismos raciales para justificar diferencias jerárquicas entre culturas.

5 En el contexto histórico de la pos-guerra, surgieron nuevas formas de presentar visualmente la economía al público, como el uso de maquetas de barreras tarifarias y el uso de lenguaje militar.
} 
el intercambio libre de bienes y se convirtió en un mercado de ideas e información, en el cual lo útil servía para asegurar predicciones económicas y mantener un orden global; naturalmente y según lo expuesto previamente, con la ayuda de un caparazón de leyes e instituciones, su funcionamiento resultaría eficaz.

Una apreciación importante al concluir la lectura del libro sería que su contribución no se limita a brindar, solamente, una mirada histórica de un fenómeno global. Lo que logra Slobodian es entrelazar un análisis desde la mirada de las Ciencias Sociales con los eventos y hechos históricos. Una de las limitaciones del trabajo podría ser el tema de la migración, el cual queda relegado como un contenido implícito en el libro. Considero que el trabajo del autor ayuda a no solo expandir la crítica sobre el neoliberalismo, sino que ayuda a entenderlo como el desarrollo de un proyecto de humilde importancia intelectual a un proyecto global y de enormes magnitudes. Además, nos demuestra cómo es que una ideología puede resultar tan atractiva y aceptada en las esferas más poderosas y, además, expone cuáles fueron las condiciones necesarias para que el proyecto se propague. Es por ello que hay que destacar el recurrente uso de fuentes primarias, como cartas y discursos de los principales actores. En estas fuentes, se evidencia la persuasiva narrativa que querían compartir con el mundo. Hoy en día, según la perspectiva neoliberal, el acelerado intercambio de información alimenta la sabiduría del mercado con el fin de consolidar orden, lo que genera una subordinación flexible de los individuos a los mandatos del mercado. Es inevitable que este libro invite al lector a reflexionar sobre las condiciones del mercado global, el rol de las instituciones y, también, a identificar qué intenciones están detrás de los cambios políticos en ambos. 